\title{
Relações entre cultura organizacional e trabalho docente no Instituto Federal do Rio Grande do Norte ${ }^{1}$
}

\author{
Relationship between organizational culture and teacher work at the \\ Federal Institute of Rio Grande do Norte
}

\section{Relaciones entre cultura organizacional $y$ trabajo del profesor en el Instituto Federal de Rio Grande do Norte}

\author{
Jássio Pereira de Medeiros² \\ Instituto Federal de Educação, Ciência e Tecnologia do Rio Grande do Norte, Professor \\ Leonor Lima Torres ${ }^{3}$ \\ Universidade do Minho, Portugal, Professora e Investigadora
}

Resumo: No presente estudo objetivou-se analisar as relações entre os construtos Cultura Organizacional e Trabalho Docente no Instituto Federal de Educação, Ciência e Tecnologia do Rio Grande do Norte (IFRN), mediante a proposta de expansão da educação profissional no Brasil. Para tanto, recorreu-se à construção de um modelo teórico apoiado, principalmente, nas discussões de Torres (2004) sobre cultura escolar, cultura organizacional escolar e cultura organizacional de escola e nas discussões de Mancebo (2007) sobre precarização, intensificação, flexibilização, descentralização e avaliação do trabalho docente. Recorreu-se ao método do estudo de caso, que adotou o IFRN como campo de observação. Para o levantamento dos dados foi administrado um inquérito por meio de questionário a 213 professores. Os resultados obtidos sugerem como destaque, entre as variáveis de cultura organizacional, aquela voltada para os valores e normas organizacionais, sendo esta a principal variável a influenciar na realização do trabalho do professor, com ênfase para a sua (in)satisfação com a remuneração recebida,

\footnotetext{
Os autores agradecem ao Centro de Investigação em Educação (CIEd), Instituto de Educação da UMinho (UID/CED/1661/2013 e UID/CED/1661/2016), que financiou parcialmente este trabalho por meio de fundos nacionais da FCT/MCTES-PT.

2 Doutor em Ciências da Educação pela Universidade do Minho; Mestre em Administração pela Universidade Federal do Rio Grande do Norte.

3 Doutora em Educação, área do conhecimento de Organização e Administração Escolar, pela Universidade do Minho; Mestre em Educação, especialidade em Administração Escolar, pela Universidade do Minho.
} 
para a precarização das condições de trabalho e a intensificação do trabalho docente.

Palavras-chave: Educação profissional. Cultura organizacional. Trabalho docente.

Abstract: The present study aimed to analyze the relationship between the constructs Organizational Culture and Teaching Work in the Federal Institute of Education, Science and Technology of Rio Grande do Norte (IFRN), through the proposal of expansion of professional education in Brazil. In order to do so, we used the construction of a theoretical model supported mainly by Torres (2004) discussions on school culture, school organizational culture and school organizational of culture and Mancebo (2007) discussions on precariousness, intensification, flexibility, decentralization and evaluation of teaching work. We used the case study method, which adopted the IFRN as an observation field. To collect data, a questionnaire survey was administered to 213 teachers. The results obtained suggest that organizational culture variables are those that focus on organizational values and norms, which is the main variable that influences the achievement of the teacher's work, with emphasis on their (in) satisfaction with the remuneration received, to the precariousness of working conditions, intensification of teaching work.

Keywords: Professional education. Organizational culture. Teaching work.

Resumen: El presente estudio objetivó analizar las relaciones entre los constructos Cultura Organizacional y Trabajo Docente, en el Instituto Federal de Educación, Ciencia y Tecnología de Rio Grande do Norte (IFRN), mediante la propuesta de expansión de la educación profesional en Brasil. Para ello, se recurrió a la construcción de un modelo teórico apoyado en las discusiones de Torres (2004) sobre cultura escolar, cultura organizacional escolar y cultura organizacional de escuela y en las discusiones de Mancebo (2007) sobre precarización, intensificación, flexibilización, descentralización y evaluación del trabajo docente. Se recurrió al método del estudio de caso, que adoptó el IFRN como local de observación. Para la recogida de los datos se administró una encuesta por cuestionario con 213 profesores. Los resultados obtenidos sugieren como destaque, entre las variables de cultura organizacional, aquella volcada hacia los valores y normas organizacionales, siendo esa la principal variable a influenciar en la realización del trabajo del profesor, con énfasis 
para su satisfacción en la remuneración recibida, para la precarización de las condiciones de trabajo e intensificación del trabajo docente.

Palabras clave: Educación profesional. Cultura de la organización. Trabajo docente.

\section{INTRODUÇÃO}

$\bigcirc$ funcionamento das organizações voltadas para a educação profissional e tecnológica no Brasil se apresenta como fenômeno complexo e multifacetado, envolvendo diversos tipos de instituições, assim como diferentes relações entre professores, alunos e servidores técnico-administrativos, principalmente na nova configuração dos Institutos Federais de Educação, Ciência e Tecnologia (IFs) resultante da política expansionista do Governo federal (GIANEZINI, 2011 ).

Esses institutos surgiram no contexto de expansão e valorização da educação profissional, desencadeado a partir do ano 2003, mediante um plano estruturante de expansão da Rede Federal de Educação Profissional e Tecnológica, que, em 2010, tinha 354 campi e 321 municípios atendidos, com a perspectiva de ampliação desse número para 562 campi e 512 municípios atendidos até 2014 (MINISTÉRIO DA EDUCAÇÃO, 2015).

De acordo com Pacheco (2011), essa ampla atuação dos IFs, no que diz respeito aos diferentes níveis de ensino, traz, para os profissionais da educação, um espaço mais complexo de construção de saberes, de tal forma que, ao mesmo tempo que possibilita o diálogo simultâneo da educação básica até a pós-graduação, exige dos docentes a construção de vínculos em diferentes níveis e modalidades de ensino, a busca de metodologias que melhor se apliquem a cada ação, assim como o estabelecimento da indissociabilidade entre ensino, pesquisa e extensão. Tais necessidades e exigências podem ter implicações diretas e indiretas na forma de atuação do professor e no clima e cultura organizacional. 
Segundo Ball (2010), esse tipo de política gera tensões que ocasionam reflexos na vida cotidiana dos profissionais em educação, impondo-lhes demandas que vão além do seu horário de trabalho para conseguir dar conta das metas estabelecidas às instituições por meio de acordos de produtividade. Acrescente-se a esse novo contexto de atuação do professor nos IFs uma estrutura administrativa multicampi, que define, de forma clara, o território de abrangência de suas ações, mas, de outra forma, também traz consigo a necessidade de contratação de professores vindos de outras localidades e que acabam não estabelecendo moradia fixa no município onde o campus está localizado ou passam a viver distante de suas famílias.

A nova institucionalidade percebida a partir do plano de expansão da Rede Federal de Educação Profissional e Tecnológica traz em seu bojo diversos desafios à forma de funcionamento das diversas organizações escolares. As especificidades desse novo modelo organizativo vêm sofrendo o impacto das "orientações para ação" (LIMA, 1992), vindas dos órgãos de administração central do Governo e do contexto periférico de adoção e implementação dessas ações por parte dos atores no IFRN. A hipótese de que pode existir uma desregulação entre as orientações centrais e as "ações efetivamente realizadas" (LIMA, 1992) fomentou o desejo de compreender as manifestações culturais existentes no IFRN e a maneira como ocorrem suas interações com a forma de realização do trabalho do professor.

Assim, considerando essas novas exigências impostas pelo núcleo central de gestão da educação por melhor atuação dos profissionais responsáveis pelos serviços educacionais e por maior demanda pela prestação desses serviços, pretende-se analisar as relações entre os construtos Cultura Organizacional e Trabalho Docente no Instituto Federal de Educação, Ciência e Tecnologia do Rio Grande do Norte, mediante a proposta de expansão da educação profissional no Brasil. A abordagem teórica e metodológica desenvolvida neste artigo resulta do aprofundamento de uma das dimensões exploradas no âmbito de uma tese de doutoramento recentemente desenvolvida na Universidade do Minho (Braga, Portugal), na área das Ciências da Educação, especialidade em Organização e Administração Escolar. 


\section{CULTURA ORGANIZACIONAL ESCOLAR}

Para Martin (1992), a definição do que venha a ser cultura se constitui em um aspecto controvertido na literatura, havendo ambiguidade a respeito do conceito. Ainda segundo a autora, vários aspectos considerados cruciais são origem de múltiplas divergências quando os estudos são transpostos para o campo das organizações. A autora parte, então, do pressuposto de que não existe somente uma cultura e procura reduzir a ambiguidade conceitual em torno do assunto, identificando três abordagens de estudos culturais que agrupariam grande parte das pesquisas realizadas: 1) Integração - nessa abordagem, os participantes da organização partilham uma visão comum da organização; 2) Diferenciação - focaliza os valores expressos que são inconsistentes e opostos; 3) Fragmentação - a ambiguidade está na essência do que seja cultura organizacional. De maneira resumida, é possível depreender que a manifestação integradora seria caracterizada pela harmonia; a diferenciadora, pelo conflito; e a fragmentadora, pela multiplicidade e desconexão.

$\bigcirc$ estudo da cultura organizacional em contexto educacional exige a construção de um referencial teórico-analítico adequado às especificidades das organizações escolares, uma vez que esses contextos apresentam enquadramento político e estrutura organizacional singulares. Mais do que transferir os modelos teóricos construídos por referência a outro tipo de organizações sociais (designadamente, as empresas), importa acautelar a sua capacidade heurística na compreensão das dimensões simbólicas das escolas. Nesse sentido, Torres (2013, p. 57) argumenta que as dinâmicas quotidianas das organizações escolares refletem todo um trabalho de intercâmbio sócioorganizacional

que combina, numa disposição original, elementos reproduzidos da ordem estrutural e elementos resultantes do jogo social, da ação concreta vivida nos contextos de trabalho. A forma como cada instituição interpreta, recontextualiza e operacionaliza localmente as orientações 
centrais configura teoricamente a noção de cultura organizacional escolar.

Tais aspectos apontam para a maneira como a escola é instituída e também instituinte de uma determinada cultura que a torna única e compõe seu corpo institucional (SANTOS, 2009). Ainda segundo o autor, isso quer dizer que a escola, enquanto espaço societal e instituída, é autoconstrução; é um resultado sócio-histórico, o que a torna também instituinte. Nessa relação instituinte e instituída, a escola somente pode ser instituição ao se concretizar nos sujeitos que ela cria, sendo construída dentro de uma multiplicidade de fatores que se desenvolvem em várias inter-relações contendo estruturas organizadoras e organizadas.

Assim, coloca-se em evidência o fato de que a instituição educativa não se limita a reproduzir uma cultura que lhe é exterior, mas produz ela própria uma cultura específica. O próprio Chervel (1998, p. 193) reconhece que "apesar de vinculada à sua tarefa de formação, de educação e de instrução, a escola funciona como um sistema autorregulado e largamente autônomo." Para o autor, não se encontra na escola apenas a cultura escolar como cultura adquirida, isto é, a escola enquanto difusora da cultura, mas também como produtora e espaço de sua origem (cultura organizacional escolar, no entendimento de Torres, 2013).

Considerando esse cenário, Candido (1977, p. 107) afirma que "se há uma organização administrativa igual para todas as escolas de determinado tipo, pode-se dizer que cada uma delas é diferente da outra, por apresentar características derivadas de sua sociabilidade própria." Desse modo, os sistemas de relações dos diferentes grupos que fazem parte da escola se apoiam nos valores simbólicos e nos rituais que acontecem em seu interior, o que implica dizer que a estrutura organizacional da escola não está amparada apenas em um plano racional determinado pela burocracia. A escola equivale, pois, a algo mais amplo, “compreendendo não apenas as relações ordenadas conscientemente, mas, ainda, todas as que derivam de sua existência enquanto grupo social." (CANDIDO, 1977, p. 107). 
Essa posição de Candido é ratificada por Nóvoa (1992, p. 25), quando esse último enfatiza que o "funcionamento de uma organização escolar é fruto de um compromisso entre a estrutura formal e as interações que se produzem no seu seio, notadamente entre grupos com interesses distintos." Tais considerações percebem uma relação direta entre o estrutural e o cultural, não de forma sobreposta ou obedecendo a uma relação dicotômica, mas de maneira inter-relacionada, partindo do princípio de que o cultural e o estrutural se influenciam mutuamente. Nesse contexto, o estrutural e o simbólico, os aspectos normativos do sistema de ensino e a autonomia escolar, o instituído e o instituinte estão permanentemente como condição histórica, sociológica, filosófica e política para o desenvolvimento e para a configuração do espaço escolar (SANTOS, 2009).

Nessa ótica, destaca-se a cultura organizacional escolar como aquela que vislumbra diferentes perspectivas acerca das relações de força e interesses no interior da organização, das normas formais e informais, das formas de controle da organização para com os indivíduos nela inseridos, do processo de ensino-aprendizagem, dos rituais, cerimônias e símbolos que o tempo todo fazem e refazem a cultura nesse nível meso de análise.

De fato, progressivamente, passou-se, como afirma Barroso (2005), para o contexto da realidade educativa portuguesa, de um sistema escolar para um sistema de escolas e de uma política educativa nacional para políticas educativas locais. Essa maior visibilidade social da escola enquanto organização e, consequentemente, uma maior importância dada ao seu estudo, contribui, entre outros fatores, para o desenvolvimento dos estudos sobre as culturas organizacionais escolares (BARROSO, 2005).

Não se poderá, portanto, desconsiderar que, tendo em vista uma cultura escolar global de perspectiva homogeneizante, deve também ser ponderada uma realidade local e particular distinta, que, frequentemente, intervém ativamente sobre as orientações e diretrizes provenientes do nível macro. E é baseado nesse cenário que, ao se interrogar acerca da eficácia de reformas, normas e medidas legislativas, não se pode ignorar que a sua implementação transcorre a partir de uma reinterpretação e de ajustamentos a contextos diversos, com uma ação decisiva. 
Isto significa que, ao se falar da cultura escolar, não se pode ficar no nível macro do sistema (o quadro formal-legal); é preciso ir ao interior das escolas "concretas" para detectar as suas especificidades e o campo de determinação resultante das práticas dos seus atores. A capacidade que cada escola possui de produzir a sua própria cultura (no quadro de um conjunto de constrangimentos externos) está intimamente ligada com o jogo de relações entre as estruturas formais e informais da organização (BARROSO, 2005).

Assim, Torres (2011) acredita que o avanço nos estudos acerca da cultura organizacional em contexto escolar passou a demandar maior aprofundamento em relação às definições até então colocadas para cultura escolar e cultura organizacional escolar. Segundo a autora, essa terceira via de estudos estaria voltada para os fenômenos que se interpõem entre o ator e o sistema, ou seja, "os valores, as práticas e crenças enraizadas nas lógicas de ação coletivas e erigidas em modelo de ação, as manifestações identitárias nascidas das esferas da informalidade." (TORRES, 2013, p. 58). Essa terceira via de estudos da cultura no contexto escolar foi denominada pela autora cultura organizacional de escola (TORRES, 2015).

\subsection{CULTURA ORGANIZACIONAL DE ESCOLA}

De acordo com Torres (2013, 2015), em um contexto marcado por novas formas de regulação da educação, percebidas por meio do uso de mecanismos de controle sobre as escolas e várias formas de prestação de contas (accountability) com foco no desempenho numérico da instituição escolar, as escolas são compelidas a colocar em marcha formas de adaptação contextual às pressões provenientes do sistema escolar e da comunidade local. A adaptação contextual leva à criação de um modus operandi que acaba sendo instituído, de maneira não formal, ao longo do tempo em cada escola concreta: "São estes modos de ser e de fazer coletivamente construídos nas escolas, que ultrapassam e estão para além das orientações normativas e estruturais que permitem aceder à cultura organizacional de escola." (TORRES, 2013, p. 58, grifo do autor). 
Os pesquisadores da cultura organizacional de escola procuram, entre aspectos diversos, entender como ocorrem as diferentes formas de assimilação de uma cultura hegemônica por grupos culturais diversos; que marcas de identidade são produzidas nas relações socioculturais entre professores e alunos, e como a escola é reinterpretada por diferentes grupos socioculturais (SANTOS; CASTRO, 2012).

De maneira geral, pode-se afirmar que o interesse principal dessa categoria cultural reside na descrição das manifestações de uma ou mais culturas no interior da escola e na apreciação de suas relações com o instituído da cultura escolar hegemônica. Como lembra McLaren (1997), historicamente poucos estudos, em especial no Brasil, estão voltados para as questões culturais, uma vez que apenas recentemente novas possibilidades de estudos surgiram nesse campo, dirigidas para aspectos do multiculturalismo (ou diversidade cultural).

A escola será visualizada, portanto, como uma entidade sociocultural constituída por grupos, que, em suas mútuas relações, vivenciam códigos e sistemas de ação, fazendo dela instrumento e produto da cultura. Nessa perspectiva, a escola não pode ser reduzida à sua estrutura de cargos e funções, tampouco aos graus e modalidades de ensino ministrados, ou ao somatório de salas de aula onde os professores são individualmente responsáveis pela prática pedagógica que desenvolvem. Ela constitui um organismo vivo e dinâmico. Possui, além de uma estrutura burocrática, uma constituição cultural e simbólica que lhe confere vida própria e lhe permite responder às demandas e limitações, impostas pelo sistema que a mantém e pelo meio social a que atende (CÂNDIDO, 1977, p. 108).

Ao considerar a unidade escolar em todas as suas dimensões, essa abordagem permite que se levem em conta os diferentes interesses e motivações, manifestados pelos atores presentes na vida da instituição, individualmente ou em grupos, e os conflitos que aí se manifestam. Não tomando a cultura como um valor integrador e uniformizante do agir e do pensar na escola, são abertas as possibilidades de percepção dos grupos e subculturas específicos que aí se formam e ganham vida no exercício das práticas que desenvolvem (TORRES, 1997, p. 41). Nessa perspectiva, a cultura organizacional de escola é a expressão dos denominadores comuns da cultura escolar e pode ser revelada 
a partir da identificação dos traços culturais marcantes na instituição, que se organizam em configurações simbólicas ou de sentido, permitindo a definição de diferentes contextos simbólicos (GOMES, 1993, p. 82-84).

Depreende-se, portanto, que a cultura organizacional, seja nas organizações, de maneira genérica, seja no contexto das organizações escolares, não pode ser considerada monolítica ou harmônica, no que tange às relações entre os integrantes da escola. $\bigcirc$ que se tem é a instituição escolar formada por um tecido de subgrupos possuidores de uma cultura própria e com uma forma particular de perceber sua vida dentro da escola. É o que acontece com os docentes, conforme é discutido na próxima seção.

\section{TRABALHO DOCENTE}

Brzezinsk e Garrido (2007) definem trabalho docente como a expressão do saber pedagógico, sendo ele fundamento e produto da atividade docente que acontece no contexto escolar, ou fora dele, em instituições sociais, historicamente construídas. Segundo as autoras, tal entendimento demonstra a dimensão criadora e complexa da práxis pedagógica, visto que o trabalho representaria fruto do movimento da pesquisa sobre as práticas e representações docentes que ora são discutidas.

Contemplando a conjuntura atual, novos requisitos educacionais passaram a ser exigidos e foram articulados aos novos processos de reestruturação educativa. As políticas neoliberais para a educação, impulsionadas a partir da década de 1970 e que ganharam mais força no Brasil nos anos 1990, têm considerado o princípio da competência do sistema escolar, pela promoção de mecanismos de controle de qualidade externos e internos à escola, que implicam uma subordinação do sistema educativo ao mercado, ao mesmo tempo que propõem modelos gerencialistas de avaliação do sistema (HYPOLITO; VIEIRA; PIZZI, 2009).

Outra característica contida nessas políticas é o uso combinado da centralização e da descentralização. A centralização estaria presente no controle 
de aspectos pedagógicos, fazendo-se uso de mecanismos de avaliação nacional (sistemas de avaliação em larga escala), reformas curriculares objetivando a adoção de um currículo nacional (APPLE, 1994; MOREIRA, 1995) e programas de formação para professores a serem executados de forma aligeirada, tendo para isso o auxílio da Educação a Distância (FREITAS, 2002; SANTOS, 2004). Já a descentralização ocorreria por meio de transferências de responsabilidades para entes federativos locais, caso dos municípios brasileiros, ou, ainda, o repasse de responsabilidades do Estado para organizações da sociedade civil organizada, além de propostas de autonomia da gestão financeira, entre outras.

No caso brasileiro, é possível perceber a implementação de tais políticas a partir das seguintes propostas que foram ou estão sendo utilizadas por parte do Governo federal: a) um sistema de avaliação baseado em provas nacionais, que leva a um ranqueamento das escolas; b) a busca por uma organização curricular central (nacional ou regional); c) a organização de programas rápidos para formação e atualização docente, que têm, como exemplo, a utilização da Plataforma Freire: ${ }^{4}$ e d) a gestão financeira descentralizada com a crescente participação de organizações da sociedade civil (caso do Programa Amigos da Escola). ${ }^{5}$ Essas práticas seriam justificadas pela interpretação que se tem do sistema escolar público como sendo ineficiente. Para tanto, surge, como solução lógica para esse problema, a adoção de critérios que possam melhorar a qualidade e a eficiência do sistema; sendo o modelo ideal aquele utilizado pelas empresas (HYPOLITO, 2005).

Depreende-se dessas proposições um discurso descentralizado voltado para a autonomia da escola, o que em tese poderia significar um fortalecimento do trabalho docente, mas também um discurso centralizador no que diz respeito ao controle pedagógico, o que representaria a negação da autonomia docente. Tal contradição demonstra que, aparentemente, o discurso do aumento da autonomia escolar e, consequentemente, o fortalecimento do

\footnotetext{
4 A Plataforma Freire é um sistema eletrônico criado em 2009 pelo Ministério da Educação, com a finalidade de realizar a gestão e acompanhamento do Plano Nacional de Formação dos Professores da Educação Básica (Parfor).

5 Programa criado pela Rede Globo de Televisão e que tem o objetivo de promover a educação básica nas escolas públicas, onde professores, pais, alunos e a comunidade em geral são convidados a participar de forma caridosa.
} 
trabalho docente e de sua influência sobre o trabalho pedagógico servem apenas para encobrir o que, efetivamente, ocorre, isto é, uma (re)centralização dos processos de avaliação do sistema de ensino e de controle do trabalho pedagógico, que, por sua vez, acabam por delimitar o conteúdo e a forma daquilo que os professores devem ensinar (HYPOLITO; VIEIRA; PIZZI, 2009). Nesse sentido, parece ficar claro que as reformas educativas propostas pelas políticas neoliberais, principalmente a partir dos anos 1990, têm um impacto significativo sobre o trabalho docente.

Nos seis primeiros anos do século XXI, Mancebo (2007) constatou que o trabalho docente recebeu forte impacto das novas ordenações assumidas pelos Estados e as decorrentes políticas implementadas para a educação e, para o estudo desses impactos, apontou a existência de dois eixos de investigação sobre o trabalho do professor: o docente enquanto trabalhador e o produto do seu trabalho. Inseridos no primeiro eixo (trabalhador docente) foram identificados cinco temas: a precarização do trabalho docente; a intensificação do regime de trabalho; a flexibilização do trabalho; a descentralização gerencial e os sistemas avaliativos. Assim é que se pretende estruturar a presente seção de acordo com essa divisão temática apresentada por Mancebo (2007).

A precarização do trabalho docente, segundo Mancebo (2007, p. 140), é o tema mais recorrente nas investigações sobre trabalho docente na literatura brasileira. A autora aponta algumas variáveis presentes nos estudos dessa natureza, "a baixa remuneração; a desqualificação e fragmentação do trabalho do professor; a perda real e simbólica de espaços de reconhecimento social; a submissão crescente e o controle do professor em relação ao seu trabalho."

A intensificação do trabalho docente, de maneira mais específica, tem sido alvo de investigações por parte de alguns pesquisadores, como Apple (1995), Hargreaves (1995), Ball (2003) e, no Brasil, Oliveira (2005, 2008), Mancebo (2007), Garcia e Anadon (2009), entre outros. A intensificação do regime de trabalho dos professores, segundo Mancebo (2007, p. 470), também vem sendo alvo de uma gama de estudos, cuja pauta envolve 
mudanças ocorridas na jornada de trabalho de ordem intensiva (aceleração na produção num mesmo intervalo de tempo) e extensiva (maior tempo dedicado ao trabalho) [...] análises sobre o aumento do sofrimento subjetivo [...]; os efeitos de neutralização da mobilização coletiva e aprofundamento do individualismo competitivo.

A expressão intensificação do trabalho docente tem sido empregada por Apple (1995), Hargreaves (1998) e Ball (2003) no cenário de investigações que buscam analisar os métodos de racionalização e controle do processo de trabalho na escola, tendo como parâmetro a organização do processo de trabalho capitalista, a administração científica do trabalho e o uso de ferramentas gestionárias nas escolas.

A flexibilização do trabalho, segundo Mancebo (2007, p. 471), está presente na literatura sobre trabalho docente de diferentes formas; entre elas, merecem destaque

a diversificação dos estabelecimentos, objetivando a expansão dos sistemas de ensino mas com contenção nos gastos públicos; a implementação de contratos de trabalho mais ágeis e econômicos, [...] as novas atribuições agendadas para os professores, alertando que o professor hoje é responsável não apenas pela sala de aula.

Além da intensificação, o trabalho dos professores tem sido fortemente flexibilizado. Exemplo disso é a introdução de professores contratados no setor público, conforme demonstram dados da pesquisa de Tenti Fanfani (2007). O número de professores sem direitos garantidos, sendo mantidos na provisoriedade do emprego, tem aumentado significativamente.

Quanto à descentralização gerencial, alguns estudos focalizam, principalmente, o fato de que os principais parâmetros educacionais continuam a ser estabelecidos, de maneira concentrada em nível macro, mas com descentralização da gestão administrativa, criando-se uma "ilusão de participação" (LIMA, 1997) e um apelo a um maior compromisso e envolvimento dos professores. Em entendimento semelhante sobre o processo de descentralização utilizado na gestão escolar, Bacelar (1997) aponta que 
não há um real processo de descentralização, mas de desconcentração das responsabilidades, de maneira que o órgão gestor central acaba por manter o controle sobre a forma de atuação das escolas.

Mancebo (2007, p. 471 ) sublinhou, ainda, a relevância das pressões performativas que submetem as instituições e docentes a rigorosos e múltiplos sistemas avaliativos; "[...] a objetivação da eficiência do professor e sua produtividade em índices e a consequente diferenciação dos docentes em função de indicadores de produtividade."

Na mesma direção, Ball (2002, p. 4) denuncia que performatividade/ desempenhabilidade

é uma tecnologia, uma cultura e um modo de regulação que emprega julgamentos, comparações e termina se revelando como meio de controle, de desgaste e de mudança. Os desempenhos dos sujeitos individuais e/ou das organizações servem como medida de produtividade ou output, ou expõem a qualidade, ou "momentos" de promoção ou inspeção.

Assim, as instituições e os docentes acabam por perder o interesse em planejar e promover atividades que não se relacionem diretamente com os indicadores de desempenho aceitos pelo sistema (BALL, 2010; ELLIOT, 2001).

\section{PROCEDIMENTOS METODOLÓGIICOS}

A abordagem metodológica mobilizada neste estudo, do ponto de vista da sistemática e da forma de abordagem do problema, inscreve-se em um paradigma predominantemente qualitativo, tendo em vista que objetiva traduzir e expressar o sentido dos fenômenos do mundo social, visando reduzir a distância entre indicador e indicado, entre teoria e dados, entre contexto e ação (VAN MAANEN, 1979). 
Com base na afirmação de Stake (1999, p. 236), de que o "Estudo de caso não é uma escolha metodológica, mas uma escolha do objeto a ser estudado", o presente estudo procura focalizar um fenômeno particular (relações entre cultura e trabalho docente), levando em conta seu contexto (IFRN) e suas múltiplas dimensões (macro e meso).

No intuito de melhor ilustrar as dimensões e as variáveis mobilizadas, apresenta-se no Esquema l a matriz de análise que orientou a pesquisa empírica.

Esquema 1 - Matriz de análise Cultura x Trabalho Docente

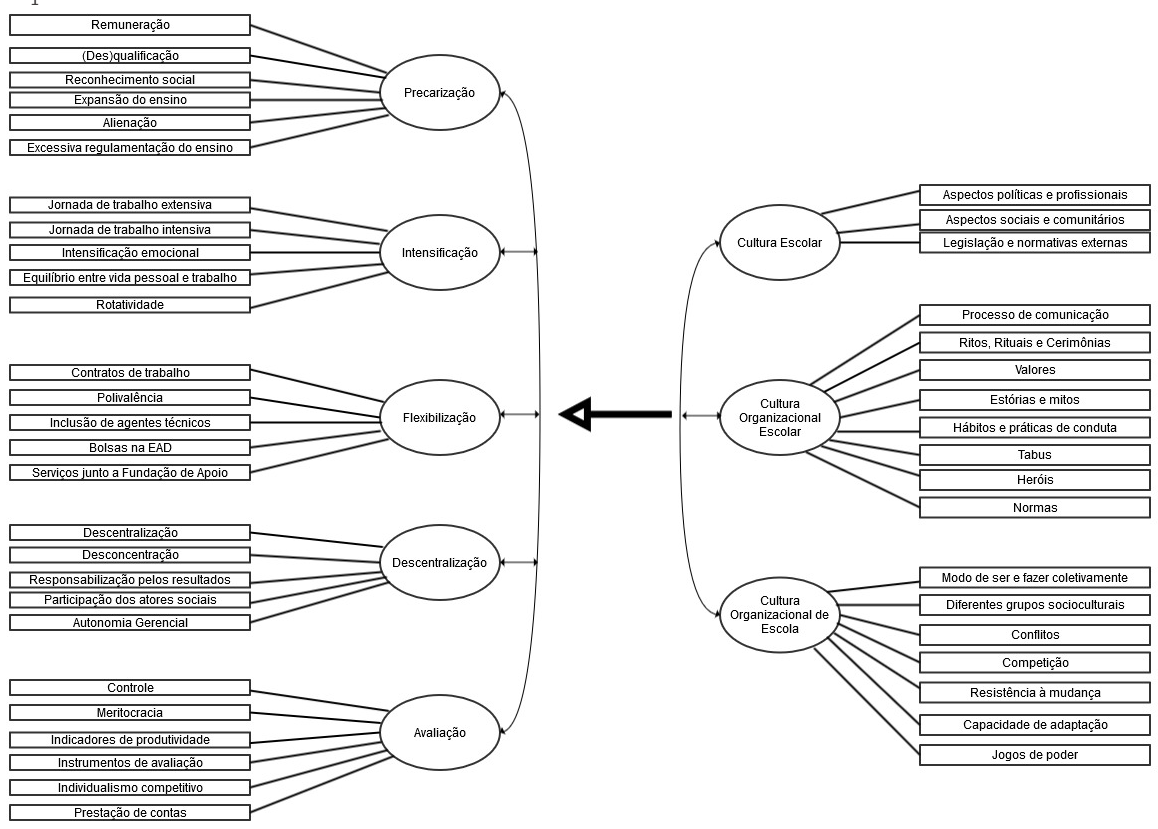

Fonte: elaborado a partir de Torres (2013) e Mancebo (2007).

Para a administração do instrumento de coleta de dados, intencionouse, inicialmente, realizar um censo com os professores dos campi Mossoró e Natal-Central do IFRN, ou seja, administrar o inquérito por meio de questionário aos 418 docentes dos dois campi.

Para o cálculo da amostra mínima de sujeitos, utilizou-se a fórmula proposta por Cochran (1977, p. 72-78), resultando em uma necessidade de 
se conseguir, pelo menos, 205 sujeitos para uma população de 418 docentes. Trabalhou-se com uma expectativa de erro de 5\%, que, para a área de ciências sociais, é um percentual aceitável, segundo Gil (1994). Do ponto de vista estatístico, isso assegura uma boa representatividade da amostra obtida e, consequentemente, a confiabilidade dos resultados. Na Tabela 1 apresenta-se a comparação entre o universo e o número de respondentes em cada campi.

Tabela 1 - Distribuição do universo e dos entrevistados por lotação

\begin{tabular}{lrrrr}
\hline \multirow{2}{*}{ Lotação } & \multicolumn{3}{c}{ Absoluto } & \multirow{2}{*}{$\%$} \\
\cline { 2 - 4 } & Universo & $\%$ & Respondentes & \\
\hline Natal-Central & 330 & 79 & 176 & 83 \\
Mossoró & 88 & 21 & 37 & 17 \\
Total & 418 & 100 & 213 & 100 \\
\hline Fonte: os autores com base no Sistema Unificado de Administração Pública (2015).
\end{tabular}

Para o alcance desses quantitativos, utilizou-se uma amostragem aleatória simples, na qual foi atribuída a cada elemento da população a mesma chance de participar da pesquisa, conforme propõe Gil (1994).

○ estudo contemplou o uso de questionário estruturado, formado por questões fechadas, medidas por meio de escalas do tipo Likert de 10 pontos. $\bigcirc$ questionário foi administrado de forma on-line mediante ferramenta de formulários disponibilizada pela empresa Google. Um link com o endereço on-line do questionário foi enviado para o e-mail institucional dos docentes e o seu retorno foi aguardado por quatro meses (outubro/2015 a fevereiro/2016).

Foi realizada, em um primeiro momento, a Análise Fatorial Exploratória (AFE), extraída por meio da análise dos componentes principais, rotação ortogonal Varimax. Os dados extraídos atenderam aos pressupostos de normalidade, linearidade, multicolinearidade, singularidade e homocesdaticidade, assim como se verificou sua confiabilidade por meio do exame da matriz de correlação, do teste Bartlett de esfericidade, do teste Kaiser-Meier-Olkin (KMO) e da avaliação das comunalidades, a partir dos quais algumas variáveis foram excluídas. 
Para decidir o número de fatores a serem extraídos pela análise fatorial, optou-se pelo critério da raiz latente. Com ele, verificou-se a formação de dois fatores, para as variáveis de Trabalho Docente, e três fatores para as variáveis de Cultura Organizacional, as quais são apresentadas, com suas respectivas cargas fatoriais, no Quadro a seguir.

Quadro 1 - Variáveis observadas do construto trabalho docente

\begin{tabular}{|c|c|c|}
\hline Fator & Variáveis observadas & $\begin{array}{l}\text { Cargas } \\
\text { fatoriais }\end{array}$ \\
\hline \multirow{4}{*}{ Remuneração } & $\begin{array}{l}\text { Meu salário é justo em comparação aos outros cargos da } \\
\text { administração federal (QTD 1) }\end{array}$ & .812 \\
\hline & Meu salário é justo em relação ao que produzo (QTD 2) & .854 \\
\hline & $\begin{array}{l}\text { Considero adequado o plano de carreira docente para o } \\
\text { Ensino Básico, Técnico e Tecnológico (QTD 4) }\end{array}$ & .820 \\
\hline & $\begin{array}{l}\text { Os docentes do IFRN se sentem valorizados pelo Governo } \\
\text { (QTD 8) }\end{array}$ & .775 \\
\hline \multirow{3}{*}{ Polivalência } & $\begin{array}{l}\text { O IFRN oferece as condições necessárias para o professor } \\
\text { atuar nos ensinos de nível básico, técnico, tecnológico e } \\
\text { de pós-graduação (QTD 22) }\end{array}$ & .872 \\
\hline & $\begin{array}{l}\text { O IFRN oferece as condições necessárias para o professor } \\
\text { atuar no Ensino, na Pesquisa e na Extensão (QTD 23) }\end{array}$ & .885 \\
\hline & $\begin{array}{l}\text { O IFRN oferece as condições necessárias para o professor } \\
\text { atuar em atividades administrativas e continuar desenvol- } \\
\text { vendo as atribuições docentes (QTD 25) }\end{array}$ & .778 \\
\hline \multirow{4}{*}{$\begin{array}{l}\text { Imagem or- } \\
\text { ganizacional }\end{array}$} & $\begin{array}{l}\text { O IFRN transmite para a população a imagem de uma } \\
\text { instituição que oferece serviços de qualidade (QC 6) }\end{array}$ & 823 \\
\hline & $\begin{array}{l}\text { O IFRN desenvolve suas ações considerando sua respon- } \\
\text { sabilidade social para com a sociedade (QC 5) }\end{array}$ & .813 \\
\hline & $\begin{array}{l}\text { O IFRN possui uma boa interação com a comunidade } \\
\text { externa (empresas, órgãos públicos) (QC 4) }\end{array}$ & .696 \\
\hline & Me identifico com a função social do IFRN (QC 9) & .651 \\
\hline
\end{tabular}




\begin{tabular}{|l|l|r|}
\hline \multirow{5}{*}{$\begin{array}{l}\text { Valores e } \\
\text { Normas }\end{array}$} & $\begin{array}{l}\text { No IFRN, todos os servidores são tratados de forma iguali- } \\
\text { tária, imparcial e justa (QC 26) }\end{array}$ & ,799 \\
\cline { 2 - 3 } & $\begin{array}{l}\text { No IFRN, o processo de ocupação de cargos eletivos é } \\
\text { feito de maneira adequada (QC 23) }\end{array}$ & $\begin{array}{l}\text { Os processos de trabalho no IFRN são coerentes, eficazes } \\
\text { (QC 21) }\end{array}$ \\
\cline { 2 - 3 } & $\begin{array}{l}\text { O IFRN rege-se por valores e princípios semelhantes aos } \\
\text { outros IFs (QC 3) }\end{array}$ &, 615 \\
\hline \multirow{5}{*}{ Rituais } & $\begin{array}{l}\text { São regularmente celebrados os êxitos que o IFRN alcan- } \\
\text { Ça (QC 13) }\end{array}$ &, 773 \\
\cline { 2 - 3 } & $\begin{array}{l}\text { O IFRN promove momentos especiais de comemorações e } \\
\text { atividades sociais e esportivas (QC 12) }\end{array}$ \\
\hline
\end{tabular}

Fonte: os autores.

Na sequência foram efetuados cálculos visando a uma análise fatorial confirmatória (AFC), mediante a Modelagem de Equações Estruturais (MEE), aqui empregada pelo software IBM SPSS Amos, versão 22. Para fins deste estudo, a análise fatorial confirmatória ocorreu via matriz de covariâncias, e o método de estimação adotado foi o da máxima verossimilhança.

Para as variáveis em estudo, o qui-quadrado dividido pelos graus de liberdade (g.l.) apresentou escore de 1,096, para as variáveis de Trabalho Docente, e 1,719, para as variáveis de Cultura Organizacional, o que implica a adequação dos dados ao modelo proposto.

Com um nível de significância estabelecido de 0,05 (Trabalho Docente) e 0,007 (Cultura Organizacional), para a estimativas, foi possível constatar que o valor da confiabilidade composta do construto e a variância extraída se apresentaram acima do valor recomendável (0,70 e 0,50, respectivamente). Por fim, ainda, foram verificadas, para análise da validade dos construtos, a validade de face, a validade nomológica, a validade convergente e a validade discriminante. 


\section{RELAÇÕES ENTRE CULTURA ORGANIZACIONAL E TRABALHO DOCENTE}

Após os testes de validade dos modelos (modelos de mensuração de Trabalho Docente e de Cultura Organizacional), tem-se, no modelo estrutural inicial, a aplicação da Modelagem de Equações Estruturais (MEE) para obtenção dos resultados efetivos do estudo. A versão de partida para o modelo estrutural segue ilustrada no Esquema 2.

Esquema 2 - Modelo estrutural

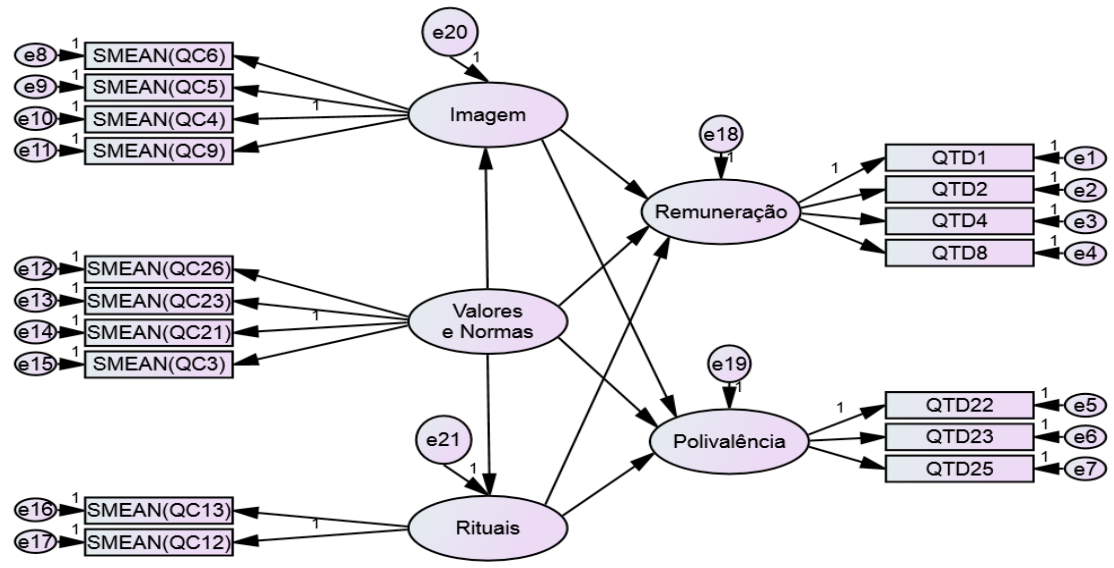

Fonte: os autores.

modelo estrutural proposto tem as variáveis referentes ao Trabalho Docente (Satisfação com a remuneração e Polivalência) sendo influenciadas por todas as variáveis de Cultura Organizacional. E, entre as variáveis de Cultura Organizacional, a variável Valores e Normas influencia a Imagem Organizacional e os Rituais praticados pela organização.

Verificando o ajustamento do modelo, o valor do qui-quadrado obtido para o modelo foi estatisticamente significativo $(\chi 2=163,341$, g.l. = $111, \mathrm{p}<0,001)$. Além disso, os índices de ajuste incremental foram maiores do que 0,90, e os índices de ajuste absoluto apresentaram valores dentro do 
limite ideal de 0,08 estabelecido pela literatura (BYRNE, 2001; HAIR JÚNIOR et al., 2005).

Assim, o modelo estrutural final foi obtido a partir do modelo de mensuração reespecificado, considerando-se as modificações propostas e utilizando-se apenas as variáveis presentes no modelo de mensuração exposto anteriormente. O modelo final produzido pelo estudo está presente no Esquema sequente.

Esquema 3 - Modelo estrutural final

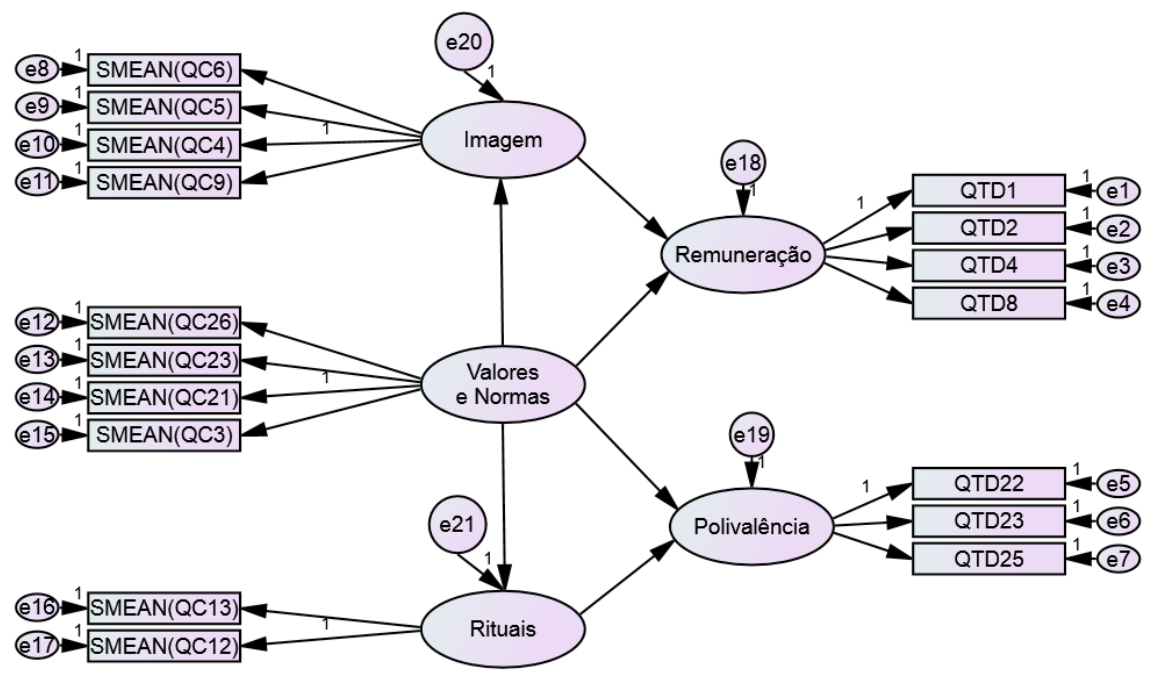

Fonte: os autores.

Complementando a análise, procede-se à verificação da matriz de resíduos normalizados do modelo. Os escores obtidos representam a variância residual das variáveis observadas dividida por uma estimativa do seu erro padrão. Como o modelo está adequado, a maior parte dos resíduos padronizados obtidos esteve dentro do intervalo $[-1,96,1,96]$, indicando a existência de consistência entre os dados e o modelo hipotético. Considerase, portanto, que os resultados do modelo estrutural podem ser considerados 
globalmente robustos e comparáveis aos estudos de Torres (2013) e Mancebo (2007), no que se refere ao agrupamento dos indicadores.

- modelo reespecificado, com suas respectivas estimativas padronizadas, é visto no Esquema 4, na sequência.

Esquema 4 - Modelo reespecificado com estimativas padronizadas

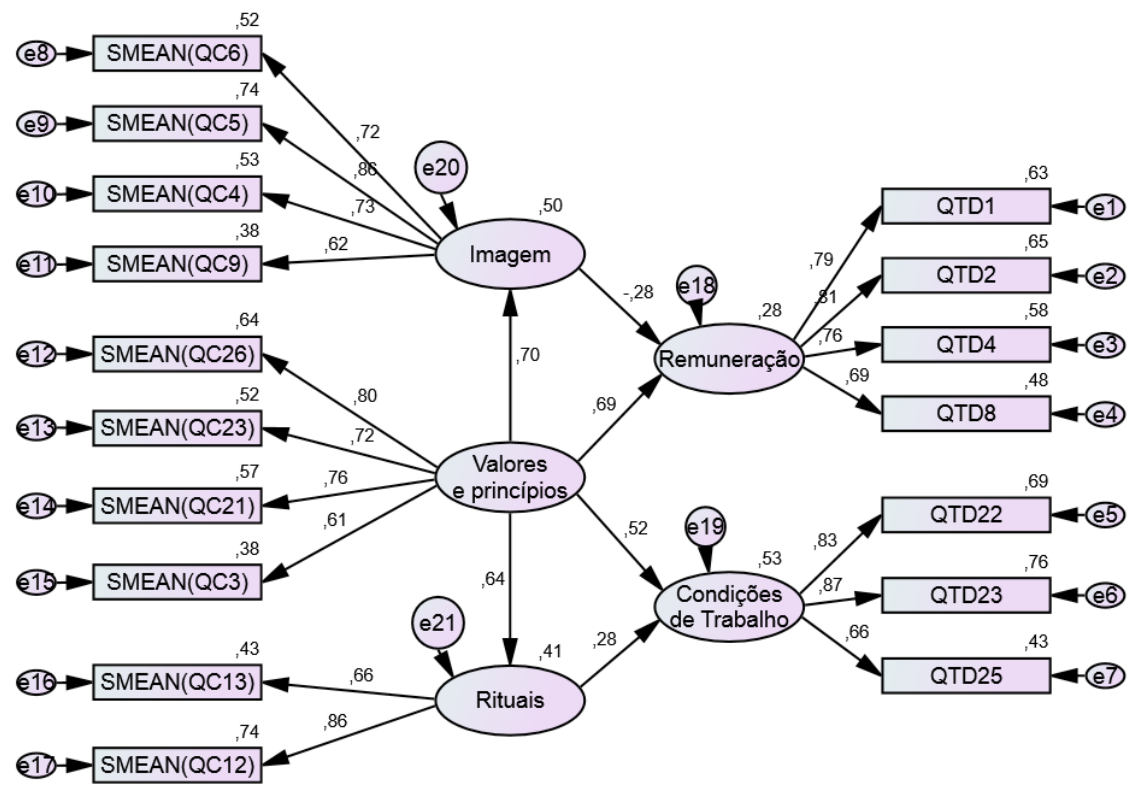

Fonte: os autores.

Os resultados alcançados por meio do modelo proposto permitem afirmar que variáveis de Cultura Organizacional interferem no trabalho docente da instituição em estudo. Entre as variáveis latentes do construto Cultura Organizacional estão a Imagem Organizacional, Valores e Normas e Rituais; e entre as variáveis latentes do construto Trabalho Docente estão a Satisfação com a Remuneração e a Polivalência. Tais resultados permitem algumas constatações.

A primeira constatação diz respeito à relevância dos indicadores associados a cada uma das variáveis latentes, uma vez que todos tiveram 
coeficientes beta superiores a 0,6, indicando que são bem explicados pelas respectivas variáveis latentes. Quanto à capacidade explicativa das variáveis latentes pertinente à relação entre Cultura Organizacional e Trabalho Docente, considera-se importante relembrar a não representação de algumas relações. De acordo com as análises estatísticas realizadas anteriormente, identificaramse relações não significativas em nível de 5\% entre as seguintes variáveis latentes: Imagem Organizacional x Polivalência e Rituais x Remuneração. Tais relações, pois, não estão representadas no modelo estrutural. Também se acredita ser relevante justificar as relações estabelecidas entre as variáveis de Cultura Organizacional. Torres (2013) já aponta para a existência de relações entre as diferentes variáveis da cultura organizacional em ambiente escolar, de maneira que, com base nisso, estabeleceram-se as relações entre as variáveis latentes, comprovadas pelas análises. Tal fato não ocorreu com as variáveis de Trabalho Docente. Nesse caso, a relação entre os construtos não se mostrou estatisticamente significante. Justificadas as relações que não ocorreram, caminha-se para a análise das relações identificadas.

Merece destaque, na análise, a variável Valores e Normas, tendo em vista que ela aparece como única variável preditora do modelo, isto é, trata-se da variável independente, a variável que não é influenciada sofre efeito de outras variáveis do modelo. Analisando a variável Valores e Normas, identifica-se um alto poder de influência na variação das variáveis Imagem Organizacional e Satisfação com a Remuneração (0,7 e 0,69, respectivamente). Esses valores sugerem o quanto de variação é esperado nas respectivas variáveis dependentes em razão da variação de uma unidade da variável Valor e Normas (independente). $\bigcirc$ poder de influência dessa variável ainda aparece nas variáveis Rituais $(0,64)$ e Polivalência $(0,52)$, sendo ainda considerados valores relevantes de interferência em tais variáveis. Isso indica que aspectos referentes ao conhecimento dos valores e princípios da instituição; tratamento igualitário para os servidores; adequação no processo de ocupação dos cargos e, principalmente, processos de trabalho coerentes e eficazes refletem na Imagem Organizacional, na Satisfação com a Remuneração, nos Rituais da organização e na Polivalência do trabalho do professor. Por se tratar de relações positivas, significa dizer que, quanto melhor for a avaliação dos Valores 
e Normas institucionais, melhor também será o julgamento quanto à Imagem Organizacional; melhor também será a Satisfação com a Remuneração e a ponderação quanto às condições de trabalho para a atuação em mais de uma atividade. Alterações positivas no julgamento dos Valores e Normas, ainda, estariam relacionadas à promoção de momentos comemorativos e de integração.

As variáveis Imagem Organizacional e Rituais atuam como variáveis que realizam uma mediação parcial entre a variável Valores e Normas e as variáveis latentes de Trabalho Docente (Satisfação com a Remuneração e Polivalência). Ao analisar o R2 dessas relações, visando verificar a qualidade do ajuste entre as variáveis a uma função linear, foi possível notar que os Valores e Normas organizacionais explicam um percentual razoável da avaliação da Imagem Organizacional (50\%) e do Rituais (41\%).

Além da relação de dependência das variáveis Imagem Organizacional e Rituais, a variável Valores e Normas também se apresentou como preditora das variáveis de Trabalho Docente (Satisfação com a Remuneração e Polivalência). A variável Satisfação com a Remuneração, no entanto, não foi suficientemente explicada pelas variáveis Valores e Normas e Imagem (28\%). Isso significa dizer que, apesar de existir uma relação significante entre as variáveis, há outras variáveis que interferem na satisfação com a remuneração e que não foram medidas no presente estudo. Sobressai o forte peso da variável Valores de Normas na explicação desses $28 \%(0,69)$.

Ainda merece comentário o fato de que a relação entre Imagem Organizacional e Satisfação com a Remuneração se apresentou de maneira negativa, o que sugere que, quanto melhor for a percepção docente acerca da imagem da instituição, pior é sua satisfação com a remuneração recebida. Isso pode ser explicado pelo cenário recente de transformação da institucionalidade e expansão organizacional, fato que contribuiu para a maior divulgação institucional e reconhecimento social de sua atuação. No entanto, esse cenário aparenta não ter trazido consigo tratamento para a remuneração dos docentes. Essa mesma relação negativa ainda permite outra análise, a de que quanto melhor for a percepção do professor em relação à imagem organizacional do IFRN, menos ele criticará a remuneração recebida, ou seja, 
docentes mais identificados com a imagem organizacional expõem menos sua possível insatisfação com a remuneração.

No que diz respeito à variável de Trabalho Docente intitulada Polivalência, sabe-se que ela possui uma relação de dependência com as variáveis Valores e Normas e Rituais. Cerca de 53\% das alterações da primeira variável são explicadas por essas duas últimas, apontando, mais uma vez, para a influência da Cultura Organizacional sobre o Trabalho Docente. Desses 53\%, novamente a variável Valores e Normas possui um peso de 0,52 e mais 0,28 da variável Rituais.

Constata-se, portanto, que, entre as variáveis de Cultura Organizacional aqui analisadas, aquela que exerce a maior influência sobre o Trabalho Docente, mais especificamente sobre a Satisfação com a Remuneração e a Polivalência, são os Valores e Normas organizacionais, ao passo que variáveis como Imagem Organizacional e Rituais exercem um baixo impacto sobre o trabalho docente.

\section{CONSIDERAÇÕES FINAIS}

Sabendo que o objetivo com esta pesquisa foi analisar as relações entre as problemáticas da Cultura Organizacional e do Trabalho Docente, no Instituto Federal de Educação, Ciência e Tecnologia do Rio Grande do Norte, mediante a proposta de expansão da educação profissional no Brasil, iniciamse algumas considerações com base na síntese das análises efetuadas, visando à compreensão da dimensão cultural que envolve o ambiente de trabalho dos docentes, assim como os modos como esses atores desenvolvem o seu trabalho.

Considera-se válido destacar que as relações entre Cultura Organizacional e Trabalho Docente aqui apresentadas a partir de um estudo de caso podem não ser verificadas em todas as organizações integrantes da Rede Federal de Educação Profissional, não devendo ser, portanto, generalizadas a priori. A presente pesquisa também não teve como pretensão esgotar todo o campo de estudo acerca da realidade, até porque o universo pesquisado se 
restringiu a dois campi da Instituição, dentre 21 existentes, o que impossibilita tecer comentários conclusivos para o IFRN como um todo.

Com vistas a compreender a dimensão cultural que envolve o ambiente de trabalho dos docentes do IFRN, o que se pode observar foi a criação de variáveis latentes que aglutinavam variáveis observáveis relacionadas à imagem organizacional, aos seus valores e normas e aos rituais praticados pela organização. Ou seja, o que foi revelado acerca da cultura organizacional que envolvia os docentes dos dois campi do IFRN foi uma dimensão comunitária (TORRES, 2004), a qual está circunscrita à convergência entre a ação organizacional e o contexto externo. Aqui, se destacavam, perante os docentes, alguns traços específicos que caracterizavam a cultura no IFRN, como, por exemplo, a boa imagem externa que a Instituição possuía na sociedade, em virtude do que a primeira oferece para a segunda, e as ações de responsabilidade social desenvolvidas pela Instituição. Acrescendo a esses traços uma maior abertura à comunidade local, a partir da participação de representantes da sociedade no Conselho Escolar de cada campus tem-se, nesse aspecto, certa articulação de dimensões simbólicas no interior dos campi, o que os transforma, e ao mesmo tempo o IFRN, em entrepostos culturais, isto é, espaços onde se transacionam variadas perspectivas culturais (TORRES, 2004).

Com o propósito de verificar a relação existente entre as manifestações de Cultura Organizacional e a realização do trabalho docente, foi constatada uma influência das primeiras sobre as segundas, com destaque para a variável Valores e Normas. A variável latente, Satisfação com a Remuneração, por sua vez, não foi suficientemente explicada pelas variáveis de cultura organizacional, isto é, apesar de existir uma relação significante entre essas variáveis, existem outras variáveis que influenciam a satisfação com a remuneração e que não foram medidas pelo presente estudo. No entanto, no que tange ao baixo poder explicativo das variáveis de cultura organizacional em relação a essa variável do construto Trabalho Docente, a variável Valores de Normas organizacionais surge como a mais relevante. Essa variável foi a única preditora do modelo, isto é, foi a única que não era influenciada por outras variáveis do modelo, de forma que os valores e normas organizacionais possuíam um alto poder de influência sobre a percepção da imagem organizacional e sobre a satisfação com a 
remuneração. $\bigcirc$ poder de influência dessa variável, ainda, atuava nos rituais praticados pelo IFRN, assim como nas condições oferecidas pela Instituição para desempenhar diferentes atividades laborais, sendo considerados valores relevantes de interferência em tais variáveis. Já variáveis como Imagem organizacional e Rituais exercem um baixo impacto sobre o trabalho do professor.

Ademais, foi possível concluir, a partir dos resultados deste estudo, que tanto a Cultura Organizacional quanto o Trabalho Docente ainda são construtos em desenvolvimento, visto que, apesar de se ter obtido a confirmação de algumas variáveis de modelos já existentes na literatura, outras variáveis presentes nesses mesmos modelos não foram confirmadas, o que é justificado pelo contexto sociológico no qual se inserem as temáticas.

Conclui-se, ainda, que a lei que criou os Institutos Federais possui um conteúdo voltado para o atendimento às demandas do mercado, em uma clara perspectiva empresarialista da componente cultural, utilizada como ferramenta de domínio sobre o docente, na medida em que procura disseminar valores e traços culturais voltados para resultados técnico-econômicos, mediante a responsabilização dos professores.

Esses tensionamentos advindos da ideologia (neo)liberal, propagada na administração pública brasileira por meio do Plano Diretor de Reforma do Aparelho do Estado (BRASIL, 1995), ao penetrarem nas camadas do IFRN, mediante estratégias para a formação de unidades identitárias competitivas, repercute na reconfiguração do trabalho do docente, principalmente em termos de precarização e intensificação do trabalho.

A proposta de criação dos IFs e de expansão da Rede de Educação Profissional, ainda, foi acompanhada por uma espécie de contratualização feita com os IFs, que, ao receberem tal estatuto, comprometeram-se com o alcance de várias metas, por meio da assinatura do Termo de Acordo de Metas e Compromissos (BRASIL, 2009), firmado com o Ministério de Educação, o que acaba por transformar o trabalho do professor em mercadoria a ser apropriada pelo mercado. Institui-se, com isso, um modelo normativista de gestão, baseado na racionalização dos custos (orçamento de cada campus dependente do seu 
número de alunos) e dos tempos e horários para os professores realizarem determinadas tarefas (Resolução n. 05/2014-CONSUP/IFRN) (INSTITUTO FEDERAL DO RIO GRANDE DO NORTE, 2014).

Com efeito, apesar de os estudos desenvolvidos sobre Cultura Docente não terem privilegiado as relações entre a Cultura Organizacional e o Trabalho Docente, parece pertinente as articulações aqui estabelecidas, mesmo entendendo que, no campo teórico, podem existir influências mútuas e até semelhanças de variáveis entre os dois construtos. No caso prático (IFRN) verificou-se uma relação de sobredeterminação da cultura organizacional em relação ao trabalho docente, sem desconsiderar que podem existir outras variáveis, capazes de influenciar as formas de realização do trabalho por parte do professor.

\section{REFERÊNCIAS}

APPLE, M. W. A política do conhecimento oficial: faz sentido a idéia de um currículo nacional? In: MOREIRA, A. F.; SILVA, T. T. (Org.). Currículo, Cultura e Sociedade. São Paulo: Cortez, 1994. p. 59-91.

APPLE, M. W. Trabalho docente e textos: economia política das relações de classe e de gênero em educação. Porto Alegre: Artes Médicas, 1995.

BACELAR, I. V. Escola, descentralização e autonomia. Revista de Administração Educacional, v. 1, n. 1, p. 27-37, jul./dez. 1997.

BALL, S. J. Performatividades e fabricações na economia educacional: rumo a uma sociedade performativa. Educação e Realidade, v. 35, n. 2, p. 37-55, maio/ago. 2010. Disponível em: <http://seer.ufrgs.br/educacaoerealidade/ article/view/15865/9445>. Acesso em: 03 jul. 2013.

BALL, S. J. Reformar escolas/reformar professores e os terrores da performatividade. Revista Portuguesa de Educação, v. 15, n. 2, p. 3-23, 2002.

BALL, S. J. The teacher's soul and the terrors of performativity. Journal of Education Policy, v. 18, n. 2, p. 215-228, 2003.

BARROSO, J. Políticas educativas e organização escolar. Lisboa: Universidade Aberta, 2005. 
BRASIL. Plano Diretor de Reforma do Aparelho do Estado. Brasília, DF, nov. 1995.

BRASIL. Termo de acordo de metas e compromissos. Brasília, DF, mar. 2009. Disponível em: <http://portal.ifrn.edu.br/institucional/planejamento/ arquivos/acordo-de-metas-e-compromissos-2010-2022>. Acesso em: 10 abr. 2015.

BRZEZINSK, I.; GARRIDO, E. Trabalho docente: mapeando a pesquisa em teses e dissertações brasileiras. Educação e Linguagem, n. 15, p. 60-81, jan./ jul. 2007.

BYRNE, B. M. Structural equation modeling with AMOS, EQS, and LISREL: comparative approaches to testing for the factorial validity of a measuring instrument. International Journal of Testing, v. 1, i. 1, p. 55-86, 2001.

CANDIDO, A. A estrutura da escola. In: PEREIRA, L.; FORACCHI, M. M. (Org.). Educação e sociedade: leituras de sociologia da educação. São Paulo: Nacional, 1977. p. 107-128.

CHERVEL, A. Le culture scolaire: une approche historique. Paris: Belin, 1998.

COCHRAN, W. G. Sampling techniques. New York: John Wiley \& Sons, 1977.

ELLIOT, J. Characteristics of performative cultures: their central paradoxes and limitations as resources for educational reform. In: GLEESON, D.; HUSBANDS, C. (Ed.). The performance school: managing, teaching and learning in a performative culture. New York: Routledge Falmer, 2001. p. 192-209.

FREITAS, H. C. L. Formação de professores no Brasil: 10 anos de embate entre projetos de formação. Educação e Sociedade, v. 23, n. 80, p. 136-167, set. 2002.

GARCIA, M. M. A.; ANADON, S. B. Reforma educacional, intensificação e autointensificação do trabalho docente. Educação e Sociedade, v. 30, n. 106, p. 63-86, jan./abr. 2009.

GIANEZINI, Q. A expansão dos Institutos Federais de Educação, Ciência e Tecnologia (IFETs) no Rio Grande do Sul e o ensino jurídico. In: SIMPÓSIO BRASILEIRO DE POLÍTICA E ADMINISTRAÇÃO DA EDUCAÇÃO, 25., São Paulo, 2011 . Anais... São Paulo: ANPAE, 2011.

GIL, A. C. Métodos e Técnicas de Pesquisa Social. São Paulo: Atlas, 1994. 
GOMES, R. Culturas de escola e identidades dos professores. Lisboa: Educa, 1993.

HAIR JÚNIOR, J. F. et al. Análise multivariada de dados. Porto Alegre: Bookman, 2005.

HARGREAVES, A. Os professores em tempos de mudança: o trabalho e a cultura dos professores na idade pós-moderna. Lisboa: Mc Graw-Hill, 1998.

HARGREAVES, A. Profesorado, cultura y postmodernidad: cambian los tiempos, cambia el professorado. Madrid: Morata, 1995.

HYPOLITO, Á. Global educational restructuring, school organizations, and teachers: the effects of conservative andcounter-hegemonic educational policies on teachers' work in Brazil. PhD Dissertation. University of Wisconsin, Madison, 2005.

HYPOLITO, Á.; VIEIRA, J. S.; PIZZI, L. C. V. Reestruturação Curricular e auto-intensificação do trabalho docente. Currículo sem Fronteiras, v. 9, n. 2, p. 100-1 12, jul./dez. 2009.

INSTITUTO FEDERAL DO RIO GRANDE DO NORTE. Resolução n. 5, de 21 de março de 2014. Aprova Normas Relativas à Carga Horária Docente do Instituto Federal de Educação, Ciência e Tecnologia do Rio Grande do Norte. 21 mar. 2014. Disponível em: < http://portal.ifrn.edu.br/conselhos/consup/resolucoes/2014/resolucao-no-05-2014/view>. Acesso em: 10 set. 2015.

\section{LIMA, L. C. A Escola como organização e a participação na organização} escolar - um estudo da escola secundária em Portugal (1974-1988). Braga: Universidade do Minho, 1992.

LIMA, L. C. Para o estudo da evolução do ensino e da formação em Administração educacional em Portugal. Revista da Faculdade de Educação/USP, v. 23, n. 1-2, p. 91-123, jan./dez. 1997.

MANCEBO, D. Agenda de pesquisa e opções teórico-metodológicas nas investigações sobre trabalho docente. Educação e Sociedade, v. 28, n. 99, maio/ago. 2007.

MARTIN, J. Cultures in organizations: three perspectives. New York: Oxford University; London: Sage, 1992. p. 58-76.

MCLAREN, P. Multiculturalismo crítico. São Paulo: Cortez, 1997. 
MINISTÉRIO DA EDUCAÇÃO. Expansão da educação superior e profissional e tecnológica: mais formação e oportunidades para os brasileiros. Disponível em: <http://portal.mec.gov.br/expansao/images/APRESENTACAO_EXPANSAO_EDUCACAO_SUPERIORl4.pdf>. Acesso em: 22 ago. 2015.

MOREIRA, A. F. Neoliberalismo, currículo nacional e avaliação. In: SILVA, L. H.; AZEVEDO, J. C. (Org.). Reestruturação curricular: teoria e prática no cotidiano da escola. Petrópolis: Vozes, 1995.

NÓVOA, A. (Org.). As organizações escolares em análise. Lisboa: Dom Quixote, 1992.

OLIVEIRA, D. A. O trabalho docente na América Latina: identidade e profissionalização. Retratos da Escola, v. 2, n. 2-3, p. 29-40, jan./dez. 2008.

OLIVEIRA, D. A. Regulação das políticas educacionais na América Latina e suas consequências para os trabalhadores docentes. Educação e Sociedade. v. 26, n. 92, p. 753-776, out. 2005.

PACHECO, E. Institutos Federais: uma revolução na Educação Profissional e Tecnológica. São Paulo: Moderna, 2011.

SANTOS, L. L. C. P. Formação de professores na cultura do desempenho. Educação e Sociedade, v. 25, n. 89, p. $1145-1$ 157, set./dez. 2004.

SANTOS, M. P.; CASTRO, C. B. As relações entre escola e cultura sob o olhar da sociologia da educação: uma abordagem sistêmica. Imagens da Educação, v. 2, n. 3, p. 69-78, 2012.

SANTOS, W. S. O caráter organizacional e cultural da gestão escolar: breves anotações. Acta Scientiarum Human and Social Sciences, v. 31, n. 2, p. 151-157, 2009.

SISTEMA UNIFICADO DE ADMINISTRAÇÃO PÚBLICA. Instituto Federal de Educação, Ciência e Tecnologia do Rio Grande do Norte. 2015. Disponível em: <https://suap.ifrn.edu.br/accounts/login/?next=/>. Acesso em: 10 maio 2015 .

STAKE, R. E. Investigación con estudio de casos. Madrid: Morata, 1999.

TENTI FANFANI, E. La condición docente: datos para el análisis comparado Argentina, Brasil, Perú y Uruguay. Buenos Aires: Siglo Veintiuno, 2007. 
TORRES, L. L. Cultura organizacional em contexto educativo: sedimentos culturais e processos de construção do simbólico numa Escola Secundária. Braga: Centro de Investigação em Educação da Universidade do Minho, 2004.

TORRES, L. L. Cultura organizacional em contexto escolar. In: LIMA, L. C. (Org.). Perspectivas de análise organizacional das escolas. Vila Nova de Gaia: Fundação Manuel Leão, 201 1. p. 109-152.

TORRES, L. L. Cultura organizacional escolar: representações dos professores numa escola portuguesa. Oeiras: Celta Editora, 1997.

TORRES, L. L. Culturas de escola e celebração da excelência: Cartografia das distinções em Portugal. Educação e Pesquisa, São Paulo, v. 41, p. 14191438, 2015. Edição especial.

TORRES, L. L. Liderança singular na escola plural: as culturas da escola perante o processo de avaliação externa. Revista Lusófona de Educação, n. 23, p. 51-76, 2013.

VAN MAANEN, J. Reclaiming qualitative methods for organizational research: a preface. Administrative Science Quarterly, v. 24, i. 4, p. 520-526, dez. 1979.

Recebido em 14 de dezembro de 2017 Aceito em 08 de junho de 2018

Endereços para correspondência: Avenida Senador Salgado Filho, 1559, Tirol, 59015-000, Natal, Rio Grande do Norte, Brasil; jassio.pereira@ifrn.edu.br 
